\title{
Endoscopic sclerotherapy with a high concentration of n-butyl-2-cyanoacrylate for anastomotic varices after choledochojejunostomy
}

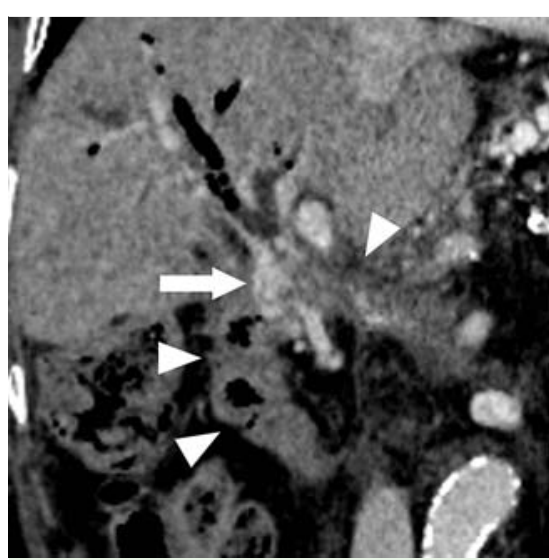

Fig. 1 Computed tomography shows anastomotic varices (arrow) in the afferent jejunal loop (arrowheads) in an 82-year-old woman who underwent pancreaticoduodenectomy for carcinoma of the papilla of Vater 6 years previously.

Anastomotic varices are an uncommon cause of variceal bleeding. After choledochojejunostomy, the anastomosed afferent jejunal loop may have a propensity to form varices, with hepatopetal flow $[1,2]$. Endoscopic sclerotherapy has the potential to cause intrahepatic obstruction of the portal vein [3-5]. This report describes endoscopic sclerotherapy with a high concentration of n-butyl-2-cyanoacrylate for anastomotic varices after choledochojejunostomy.

An 82-year-old woman presented with intermittent melena. She had undergone pancreaticoduodenectomy for carcinoma of the papilla of Vater 6 years previously. Computed tomography showed portal vein thrombosis with cavernous transformation, leading to the formation of varices around the choledochojejunostomy site (๑ Fig. 1).

Endoscopy with an upper gastrointestinal endoscope (GIF-H290; Olympus, Tokyo, Japan) was undertaken to assess the varices. A small amount of fresh blood was seen in the afferent jejunal loop, and varices were observed around the choledochojejunostomy site ( $\nabla$ Fig. 2 ). We opted to perform endoscopic sclerotherapy with a high concentration of n-butyl-2-cyanoacrylate. A total of $1.2 \mathrm{~mL}$ of glue mixture (1.0 mL of n-butyl-2-cyanoacrylate and

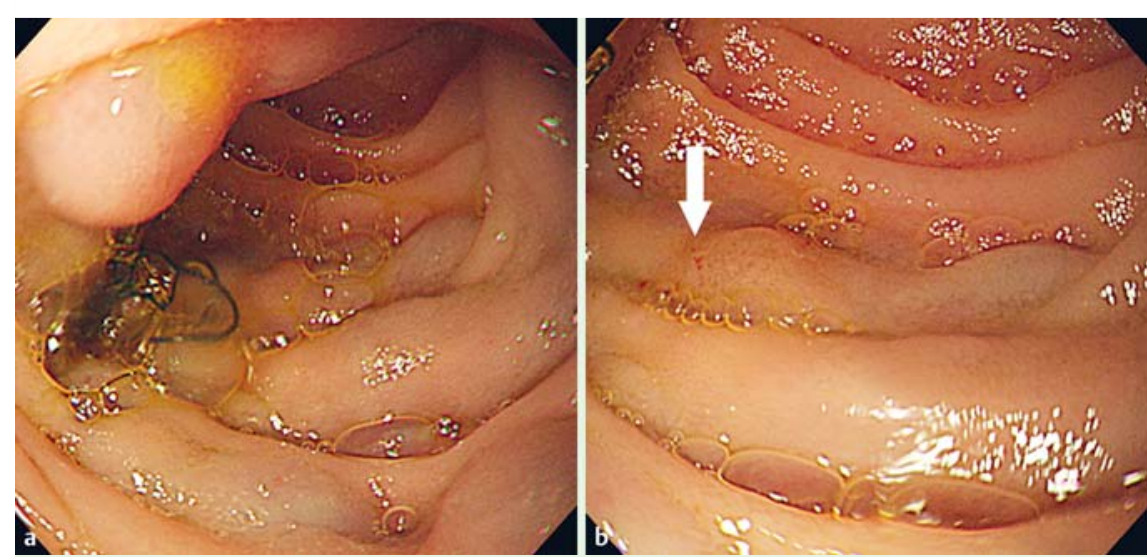

Fig. 2 Endoscopic view of the anastomosed afferent jejunal loop. a Anastomotic varices are revealed around the choledochojejunostomy site. b A small erosion (arrow) implicated in the bleeding is found on the varices.
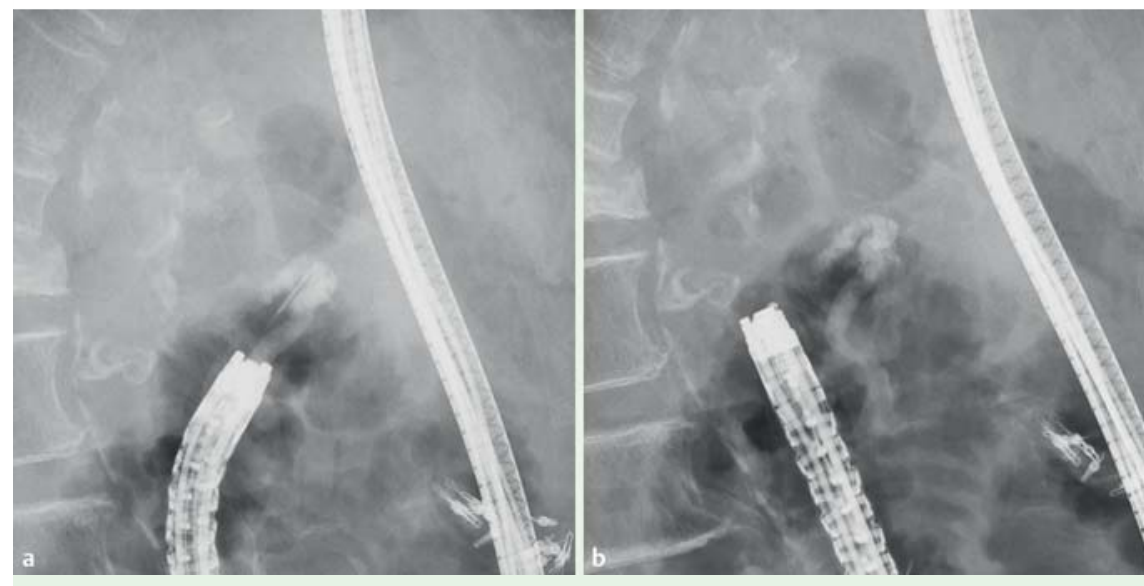

Fig. 3 Endoscopic sclerotherapy images. a A high concentration of n-butyl-2-cyanoacrylate is injected under fluoroscopic guidance. $\mathbf{b}$ The sclerosant fills the varices and polymerizes without leaking into the liver.

$0.2 \mathrm{~mL}$ of Lipiodol) was injected with a 23-gauge needle under fluoroscopic guidance ( $\bullet$ Fig. 3 ). The sclerosant filled the varices and did not leak into the liver. A computed tomographic scan showed the deposition of Lipiodol in the anastomotic varices without any deposition in the liver parenchyma ( Fig.4). The bleeding ceased without any complication, and no further bleeding was observed.

Unlike gastric varices, anastomotic varices after choledochojejunostomy drain directly into the intrahepatic portal vein within a short distance. Therefore, the rapid polymerization of the usual concentration of n-butyl-2-cyanoacrylate (ratio

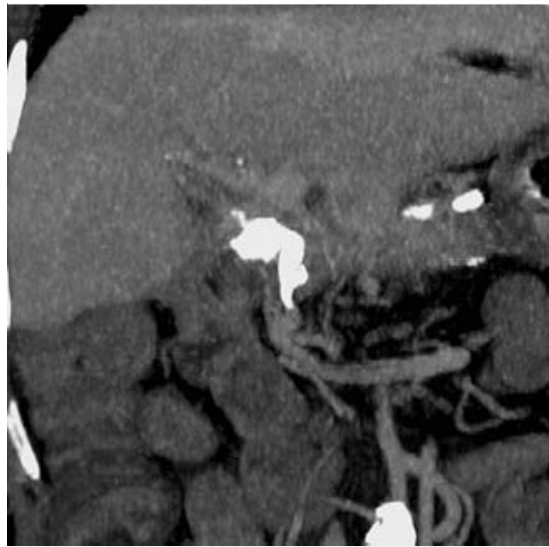

Fig. 4 Computed tomography shows the deposition of Lipiodol in the varices. 
of n-butyl-2-cyanoacrylate to Lipiodol of $1: 1$ or $1: 1.6$ ) is considered to create a risk for intrahepatic obstruction of the portal vein. To our knowledge, this is the first report of the use of a high concentration of n-butyl-2-cyanoacrylate for endoscopic sclerotherapy in a patient with anastomotic varices after choledochojejunostomy.

Endoscopy_UCTN_Code_TTT_1AO_2AD

Competing interests: None

\section{Sho Kitagawa, Takahiro Sato, Mutsuumi Kimura}

Department of Gastroenterology, Sapporo Kosei General Hospital, Sapporo, Japan

\section{References}

1 Lee DH, Kim YH, Lee YJ et al. CT findings of afferent loop varices after bilioenteric anastomosis in patients with malignant disease. AJR Am J Roentgenol 2013; 200: 1261 1268

2 Hashimoto M, Heianna J, Yasuda K et al. Portal flow into the liver through veins at the site of biliary-enteric anastomosis. Eur Radiol 2005; 15: 1421 - 1425

3 Shim CS, Cho YD, Kim JO et al. A case of portal and splenic vein thrombosis after Histoacryl injection therapy in gastric varices. Endoscopy 1996; 28: 461

4 Thijs WJ, de Groot EH, Hofstra LS. Portal and splenic vein occlusion complicating Histoacryl injection therapy in bleeding gastric varices. Endoscopy 2008; 40 (Suppl. 02): E187. DOI: $10.1055 / \mathrm{s}-2007-966412$

5 Prachayakul V, Aswakul P, Kachintorn U. leeding hepaticojejunostomy anastomotic varices successfully treated with Histoacryl injection, using single-balloon enteroscopy. Endoscopy 2011; 43 (Suppl. 02): E153. DOI: 10.1055/s-0030-1256233
Bibliography

Dol http://dx.doi.org/

10.1055/s-0034-1392259

Endoscopy 2015; 47: E321-E322

(c) Georg Thieme Verlag KG

Stuttgart · New York

ISSN 0013-726X

\section{Corresponding author}

\section{Sho Kitagawa, MD}

Department of Gastroenterology Sapporo Kosei General Hospital

Kita 3 Higashi 8

Chuo-ku

Sapporo 060-0033

Japan

Fax: +81-11-271-5320

bossa0405@yahoo.co.jp 